\title{
Evaluasi dan Perencanaan Awal untuk Meningkatkan Efektifitas IPAL Sistem Anaerobik PKS PT. Deli Muda Perkasa
}

\section{Evaluation and Initial Planning for Improved Effectiveness of Anaerob WWTP System in Crude Palm Oil Industry PT Deli Muda Perkasa}

\author{
PETRUS NUGRO RAHARDJO \\ Pusat Teknologi Lingkungan, Badan Pengkajian dan Penerapan Teknologi \\ Gedung Geostek 820, Kawasan Puspiptek, Serpong, Tangerang Selatan 15314 \\ inugardjoho@yahoo.com
}

\begin{abstract}
Palm Oil Factory PT. Deli Muda Perkasa (DMP) in Batanghari regency has been operating since 2007 and with a capacity of 60 tonnes of Fresh Fruit Bunch (FFB) per hour. But until 2015, it still has a lot of environmental problems, because the processing results of Wastewater Treatment Plant (WWTP) still does not meet environmental quality standards in accordance with applicable regulations. This activity aims to evaluate the effectiveness of anaerob WWTP in PT. DMP, identify the problems, and make a recommendation to seek some alternatives in planning to improve the effectiveness of the WWTP. The methodology used is preceded by a field survey and interviews with the person in charge of WWTP, waste water sampling, analyzing the samples in a laboratory and doing analysis especially for the WWTP. The results concluded that the effectiveness of anaerobic treatment process is still low, especially for the reduction of parameters oil/grease and Total Nitrogen, while result for BOD and COD parameters is sufficient. Optimizing the effectiveness of anaerobic processing units can be carried out by several alternatives, such as emptying all units processing pond consecutively, changing the inlet and outlet system of every treatment unit, mounting flowmeter, remining all processing ponds and total WWTP reconstruction. It also should be maintained continuously, by dredging sediment sludge periodically. Thus, it needs a proper special sludge handling and good to ensure that no contamination to the environment.
\end{abstract}

Keywords: effectivity, anaerobic treatment, proper sludge handling

\begin{abstract}
ABSTRAK
Pabrik Kelapa Sawit PT. Deli Muda Perkasa (DMP) di Kabupaten Batanghari beroperasi sejak tahun 2007 dengan kapasitas 60 ton TBS per jam. Namun hingga tahun 2015 masih mempunyai banyak masalah lingkungan, karena hasil pengolahan IPALnya masih belum memenuhi baku mutu lingkungan. Kegiatan ini bertujuan untuk mengevaluasi keefektifan IPAL anaerobic PT. DMP, mengindentifikasi permasalahannya, dan memberi rekomendasi beberapa alternatif dalam perencanaan untuk meningkatkan efektifitas IPAL tersebut. Metodologi yang digunakan yaitu diawali dengan survei lapangan, wawancara dengan penanggung jawab IPAL, pengambilan sampel air limbah, analisa laboratorium dan analisis proses pengolahan sistem anaerobik IPAL. Kesimpulan yang diperoleh yaitu efektifitas proses pengolahan anaerobik masih rendah, terutama untuk pengurangan parameter minyak/grease dan Nitrogen Total. Sedangkan untuk parameter BOD dan COD hasilnya sudah sangat bagus. Untuk mengoptimalkan efektifitas unit-unit pemroses anaerobik dapat ditempuh beberapa alternatif, misalnya pengurasan seluruh unit-unit kolam pemroses, perubahan sistem inlet dan outlet, pemasangan flowmeter, remining semua kolam pemroses dan rekonstruksi total IPAL. Selain itu juga harus dilakukan perawatan secara kontinu, yaitu dengan pengerukan lumpur-lumpur endapan secara periodik. Dengan demikian dibutuhkan penanganan lumpur endapan secara khusus dan baik untuk menjamin tidak adanya pencemaran lingkungan sekitarnya.
\end{abstract}

Kata kunci: efektifitas, pengolahan anaerobik, penanganan lumpur 


\section{PENDAHULUAN}

Dalam dua puluh tahun terakhir ini di Indonesia semakin banyak lahan-lahan baru perkebunan Kelapa Sawit, terutama di Sumatera, Kalimantan, Sulawesi, dan bahkan sudah mulai ke Papua. Pada tahun 2014 perkebunan Kelapa Sawit di seluruh Indonesia sudah mencapai 10,46 juta hektar dengan produksi CPO mencapai 29,34 juta ton ${ }^{(1)}$. Karena itu jumlah limbah cair yang akan dihasilkan secara total diperkirakan hampir mencapai 100 juta ton. Sungguh disayangkan bahwa sebagian besar pabrik-pabrik kelapa sawit yang ada di Indonedia tersebut rata-rata belum mempunyai sistem pengolahan limbah cair yang baik dan sempurna. Berbagai jenis dan sistem teknologi pengolahan limbah cair PKS telah diteliti dan diujicobakan dengan baik, namun untuk mengimplementasikannya sangat dibutuhkan koordinasi dan komitmen dari seluruh stakeholder.

Pabrik Kelapa Sawit (PKS) PT. Deli Muda Perkasa (DMP) mulai beroperasi pada tahun 2007. PKS ini berlokasi di Desa Sengkati Baru, Kecamatan Mersam, Kabupaten Batanghari, Propinsi Jambi. Berdasarkan informasi dari Manajer Produksi diketahui bahwa kapasitas pengolahan maksimal PKS DMP adalah sebesar 60 ton TBS (tandan buah segar) per jam. Sejak beroperasi pabrik ini sudah dilengkapi dengan sistem instalasi pengolahan air limbah (IPAL) dengan kapasitas yang sesuai dan bahkan sudah dirancang untuk sistem IPALnya yang mampu mengolah air limbah bila kapasitas produksi PKS ini ditingkatkan menjadi satu setengah kali dari kapasitas produksi saat ini. Berdasarkan pemantauan yang telah dilakukan oleh BLHD (Badan Lingkungan Hidup Daerah) Kabupaten Batanghari, pada dua tahun terakhir ini IPAL PKS PT. DMP mempunyai masalah yang serius, yaitu tidak optimalnya proses pengolahan air limbahnya, sehingga mengakibatkan pencemaran yang terjadi di tiga buah desa di sekitarnya, yaitu Desa Sengkati Kecil, Sengkati Gedang dan Sengkati Baru ${ }^{(2)}$. Hasil pemantauan terhadap adanya pencemaran tersebut ditunjukkan dengan menurunnya kualitas air tanah. Kondisi air tanah dangkal (sumur pantau) di sekitar IPAL tampak semakin keruh, kotor dan berbau tidak sedap, serta disimpulkan tidak cukup layak untuk dikonsumsi sebagai air bersih seperti waktu-waktu sebelumnya ${ }^{(3)}$. Demikian halnya dengan dampak terhadap air sungai yang bertindak sebagai badan air penerima effluent dari IPAL tersebut. Air sungai Desa Sengkati menjadi kotor, berwarna hitam dan berbau busuk, terutama pada musim penghujan ${ }^{(4)}$.

Karena permasalahan tersebut maka dibutuhkan satu evaluasi terhadap efektifitas IPAL, khususnya pada unit anaerobiknya, mengingat bahwa proses degradasi bahan pencemar yang dapat mengurangi beban CODBOD yang tinggi adalah proses anaerobik. Pengolahan anerobik ini akan menguraikan senyawa organik (asam lemak tinggi, asam amino dll.) dalam air limbah menjadi asam lemak rendah, asam asetat, hidrogen dan lain-lain melalui proses hidrolisis dan fermentasi ${ }^{(5)}$. Proses pengolahan secara anaerobik melibatkan bermacam-macam bakteri anaerob fakultatif (bakteri metabolisme yang tahan hidup hanya di kondisi anaerob). Dalam proses fermentasi bahan-bahan organik tersebut diuraikan menjadi $\mathrm{CO}_{2}, \mathrm{CH}_{4}$, Amonia dan $\mathrm{H}_{2} \mathrm{~S}^{(5)}$.

Tujuan dari kegiatan ini adalah mengevaluasi keefektifan IPAL anaerobik PKS PT. DMP, mengidentifikasi permasalahannya dan memberikan rekomendasi untuk pemecahan masalah tersebut, terutama dalam perencanaan meningkatkan efektifitas IPAL tersebut.

\section{BAHAN DAN METODE}

Tahapan yang dilakukan

dalam melaksanakan kegiatan ini yaitu :

a) Survei Pendahuluan

Survei awal dilakukan pada akhir bulan Mei hingga awal Juni 2015, yaitu untuk berkoordinasi dengan Pemerintah Kabupaten Batanghari dan Manajer Produksi PKS PT. DMP yang didampingi oleh Kepala Divisi Limbahnya, serta melakukan peninjauan langsung terhadap sistem IPAL PKS PT. DMP. Pada kesempatan ini juga dilakukan wawancara dengan para pejabat dan penanggung jawab daerah, serta beberapa penduduk di sekitar kawasan pabrik, yaitu di Desa Sengkati Baru. Pengukuran dimensi (panjang dan lebar, serta kedalaman) dari setiap unit pemroses juga dilakukan pada tahapan ini.

b) Studi Literatur

Dalam studi pustaka dapat dilakukan berbagai kegiatan yang bertujuan untuk memperoleh informasi-informasi ataupun data yang berkaitan dengan sistem pengolahan limbah cair PKS dan semua itu dapat dijadikan referensi dalam menganalisa permasalahan yang timbul, terutama yang berhubungan dengan ketidak-idealan proses yang seringkali terjadi pada sistem IPAL suatu PKS, terutama pada proses Anaerobiknya.

c) Sampling

Pengambilan sampel air limbah pada titik-titik lokasi instalasi pengolahan air limbah PKS PT. DMP, khususnya mulai proses awal sampai pada unit anaerobik. Pengambilan sampel dilakukan oleh pihak Laboratorium yang telah ditunjuk oleh Kantor BLHD 
setempat. Sistem pengambilan sampel harus memenuhi standar yang berlaku, yaitu mulai dari cara penentuan titik lokasi, persiapan peralatan untuk sampling, pengambilan sampel dan penyimpanan sampel-sampel limbah cair dalam coolbox sebelum dibawa dan dikirim ke Laboratorium. Jumlah sampel yang diambil adalah 4 buah, yaitu pada bagian inlet cooling pond 3 , outlet acidification pond, outlet primary anaerobic pond dan secondary anaerobic pond.

d) Analisa Laboratorium

Keempat sampel yang telah diambil pada saat sampling, kemudian dianalisa di Laboratorium PT. Global Quality Analitical. Analisa parameter yang diutamakan adalah BOD, COD, Nitrogen Total dan Oil/Grease.

e) Analisis hasil kualitas pengolahan limbah cair secara anaerobik di laboratorium.

\section{HASIL DAN PEMBAHASAN}

\subsection{Diagram Alir Proses Pengolahan Air Limbah Eksisting}

Diketahui bahwa kapasitas produksi PKS PT. DMP adalah 60 ton TBS per jam, namun karena keterbatasan ketersediaan bahan baku, maka rata-rata perhari hanya melaksanakan pengolahan sebesar \pm 35 ton TBS/jam. Dengan operasional rata-rata per hari seperti itu, maka diperkirakan jumlah limbah cair maksimum ratarata yang dihasilkan, yaitu sebesar $65 \mathrm{~m}^{3} /$ jam . Data Produksi pada bulan April dan Mei 2015 yang diperoleh dari Manajer Produksi ditunjukkan pada Tabel 1. Data produksi menunjukkan pengoperasian PKS yang berkisar antara $43-48$ Ton TBS/jam. Dengan demikian jumlah air limbahnya juga melebihi dari rata-rata, yaitu lebih dari $65 \mathrm{~m}^{3} /$ jam. Setiap ton TBS dapat dikonversi oleh PKS menjadi 0,2 ton Crude Palm Oil (CPO) dan menghasilkan 0,66 ton limbah cair $^{(6)}$. Jadi jumlah limbah cair PKS PT. DMP tergolong jauh lebih besar dari pada rata-rata limbah cair yang dihasilkan dari PKS yang lainnya.

Tabel 1 : Data Produksi April dan Mei 2015

\begin{tabular}{clcc}
\hline NO & Data Produksi & APRIL 2015 & MEI 2015 \\
\hline 1 & Olah TBS (kg) & 11.330 .490 & 13.705 .000 \\
2 & Kapasitas (Ton/jam) & 43,082 & 48,004 \\
3 & Waktu Operasi (Jam) & 263 & 285 \\
\hline
\end{tabular}

PKS DMP memiliki Unit IPAL yang sejak awalnya sebenarnya juga sudah disesuaikan dengan kapasitas maksimum pabrik. Secara skematis Unit IPAL PT. DMP ditunjukkan pada Gambar 1. Berdasarkan laporan dari pihak PT. DMP diperoleh informasi bahwa Unit IPAL secara lengkap terdiri dari 15 kolam terbuka dan berdasarkan Master Plan awal, keseluruhan kolam mempunyai kedalaman yang sama, yaitu 6 meter $^{(7)}$. Berdasarkan gambar desain dalam Master Plan IPAL PT. DMP, kolam-kolam tersebut pada umumnya berbentuk persegiempat dengan luas permukaan dasar setiap kolam mempunyai luas permukaan yang jauh lebih kecil dari pada luas bagian atasnya. 15 kolam pengolahan air limbah tersebut terdiri dari :

- 3 buah kolam (pond) pendinginan (Kolam 1, 2 dan 3) yang masing-masing mempunyai ukuran berbeda.

- 1 buah kolam Asidifikasi (Kolam 4)

- 2 buah kolam Anaerobik Primer dengan dimensi ukuran yang sama (Kolam $5 \& 6$ )

- 2 buah kolam, Anaerobik Sekunder dengan ukuran yang berbeda (Kolam $7 \& 8$ )

- 2 buah kolam Fakultatif dengan ukuran yang berbeda (Kolam 9 \& 10)

- 1 buah kolam besar Aerobic (Kolam 11)

- 1 buah kolam Sedimentasi Primer (Kolam 12)

- 1 buah kolam Sedimentasi Sekunder (Kolam 13)

- 2 buah kolam Akhir (Kolam 14 \& 15).

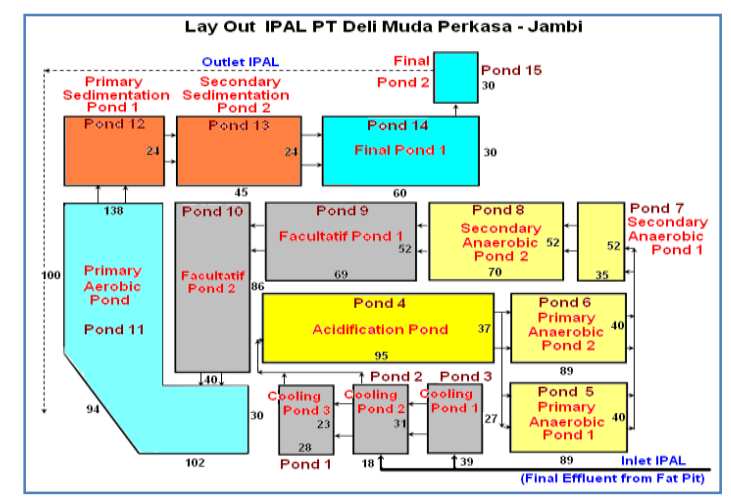

Gambar 1. Skema diagram alir proses pengolahan air limbah eksisting dan tata letaknya.

\subsection{Kondisi Fisik IPAL Eksisting Terkini dan Jalannya Proses Pengolahan Anaerobik}

\section{a) Influent}

Influent IPAL berasal dari 2 sumber, yaitu Supernatan Fat Pit dan Air bekas pencucian unitunit pemroses PKS. Air limbah yang berasal dari Fat Pit rata-rata bersuhu sekitar $60^{\circ} \mathrm{C}$ lebih. Kondisi Fat Pit seperti ditunjukkan pada Gambar 2. Seluruh air limbah dari Fat Pit ini terukur jumlah debitnya melalui sebuah Flowmeter. Sumber air limbah dari air bekas pencucian unitunit pemroses PKS tidak diketahui pasti apakah juga terukur jumlah debitnya. Air limbah ini ditampung dalam suatu bak yang dirancang mempunyai outlet overflow dan mengalirkan air 
tampungan tersebut secara gravitasi ke saluran terbuka menuju kolam pendingin.

\section{b) Proses Pendinginan}

Untuk menurunkan temperatur air limbah (influent) yang berasal dari Fat Pit, maka suatu saluran khusus yang tertutup melalui sistem perpipaan dialirkan ke kolam pendingin (Cooling Pond) ke 2 dan ke 3 . Kolam pendingin pertama tampaknya sudah tidak digunakan lagi, karena sudah terlalu banyak pengendapan yang telah terlanjur mengeras pada permukaannya. Pada kolam pendingin kedua dan ketiga sebenarnya juga terjadi hal yang sama seperti kolam pendingin pertama, namun pengaliran air limbah masih dapat terlihat walaupun mengalami channelling (pengaliran tidak efektif yang hanya membentuk beberapa saluran kecil pada bagian permukaan kolam). Oleh sebab itu dapat dipastikan bahwa waktu tinggal di kedua kolam tersebut juga sudah jauh berkurang dibandingkan dengan yang telah direncanakan semula. Uap air limbah (karena panas dari effluent Fat Pit) masih terlihat. Karena itu sebelum air limbah dari kolam pendingin masuk ke dalam kolam Asidifikasi, terlebih dahulu dicampur dengan air limbah yang sudah dingin yang berasal dari kolam aerobik. Pada titik pencampuran dua aliran tersebut masih tampak asap uap air limbah yang menunjukkan temperaturnya masih lebih tinggi dari temperatur ambient (lingkungan). Pada umumnya air limbah pada unit kolam pendinginan ini mempunyai sifat asam, artinya derajat keasamannya jauh lebih rendah dari 7 .

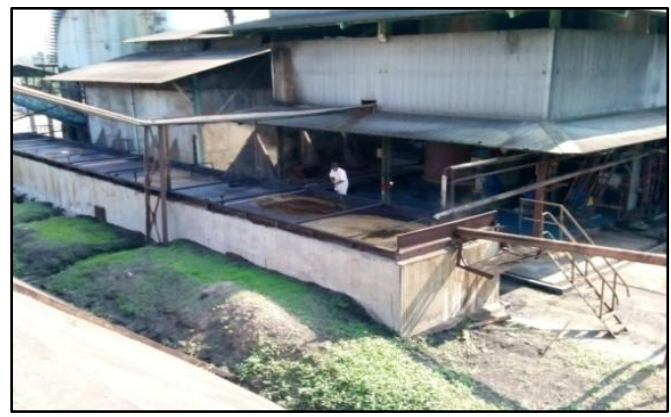

Gambar 2. Kolam Fat Pit sebagai pengumpul air limbah dari PKS.

\section{c) Asidifikasi}

Kolam Asidifikasi adalah kolam pengasaman. Unit ini dimaksudkan agar air limbah yang akan mulai diproses pada unit pemroses berikutnya, yaitu kolam anaerobik, mempunyai suasana keasaman yang sesuai dengan syarat pada kolam anaerobik (sekitar netral atau $\mathrm{pH}$ dalam range 6 - 9). Apabila keasamannya masih di bawah 6, maka biasanya harus dilakukan penambahan basa agar $\mathrm{pH}$ naik hingga 6 - 9 .
Pada kolam asidifikasi (Pond 4) kondisinya juga tidak jauh berbeda, yaitu telah terjadi pendangkalan akibat banyaknya lumpur endapan (Gambar 3). Pengamatan yang telah dilakukan pada survei awal Juni 2015 menunjukkan bahwa kedalaman kolam asidifikasi hanya sekitar $1 \frac{1}{2}$ meter. Jadi dapat dipastikan bahwa waktu tinggal sudah jauh lebih kecil dibandingkan dengan apa yang direncanakan sejak semula. Pencampuran air limbah dari kolam pendinginan dan yang dari kolam aerobik hanya semata-mata untuk menurunkan temperatur air limbah. Apabila sirkulasi sebagian air limbah dari kolam aerobik ke kolam asidifikasi dimaksudkan untuk memberikan lumpur aktif, maka cara ini tidak tepat karena kondisi suhu air limbah yang masih belum mencapai normal akan menyebabkan mikroba tidak akan dapat berfungsi, bahkan akan dapat mengakibatkan matinya mikroba aerobik. Demikian juga dengan kondisi yang berbeda dari aerobik ke anaerobik, maka lumpur aktif yang berasal dari kolam aerobik tidak akan dapat berfungsi pada kolam yang beroperasi tanpa aerasi atau tanpa pengkayaan oksigen.

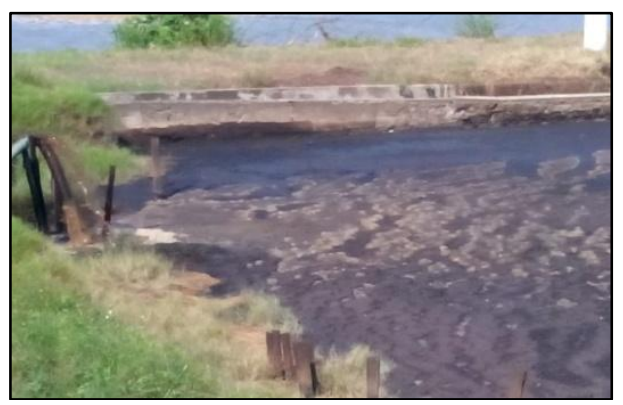

Gambar 3. Kolam Asidifikasi yang sudah mengalami pengerasan karena pengendapan dipermukaannya.

\section{d) Proses Anaerobik}

Proses pengolahan anaerobik pada IPAL diakomodasi pada 4 (empat) buah kolam anaerobik. 2 Kolam anaerobik pertama adalah anaerobik primer (Pond 5 dan 6 ) dan yang 2 kolam anaerobik berikutnya adalah anaerobik sekunder (Pond 7 dan 8). Namun karena timbulnya pendangkalan-pendangkalan yang terus menerus dan kurangnya perawatan untuk pengambilan lumpur endapan di seluruh kolam pada IPAL, maka secara umum volume efektifnya menjadi sangat berkurang dan dengan sendirinya waktu tinggal yang diharapkan lebih dari 8 hari di setiap kolam Anaerobiknya, pada kondisi saat ini tidak mencapai 2 hari. Untuk mengetahui persis kondisi dan efisiensi setiap proses dibutuhkan lebih banyak survei mendetail dan lebih terinci. Memang di Pond ke 7 dan 8 (kolam anaerobik sekunder) endapan lumpur dan pengerasan endapan lumpur di permukaan 
kolam sudah berkurang dibanding dengan kolamkolam anaerobik primer, namun kedalaman kolam juga relatif sama, yaitu sekitar 1,5 hingga 2 meter saja. Dapat dipastikan juga bahwa dengan keadaan seperti itu, maka pengaliran air limbah juga terjadi secara channelling, sehingga proses pengolahan secara anaerobik justru tidak berlangsung dengan baik.

\subsection{Hasil Analisis Kuantitas Proses Pengolahan}

Berdasarkan informasi yang diperoleh dari bagian produksi, diketahui bahwa operasi PKS PT. DMP jarang sekali mencapai kapasitas maksimal yang sebesar 60 ton TBS/jam (lihat Tabel 1). Rata-rata operasi hanya mengolah 35 $45 \mathrm{TBS} / \mathrm{jam}$. Dengan demikian rata-rata jumlah limbah cair yang dihasilkan sekitar $65 \mathrm{~m}^{3} / \mathrm{jam}$. Dari data dimensi unit-unit pemroses dalam IPAL seperti yang ditunjukkan pada Gambar 1, dapat diambil suatu pendekatan untuk menentukan volume efektif dari setiap unit kolam pemroses.
Luas permukaan atas kolam pada permukaannya (bagian atasnya) adalah sesuai dengan panjang kali lebar dari ukuran yang tertera pada gambar Master Plan IPAL tersebut. Tetapi luas dasar kolam akan jauh lebih kecil, karena dinding kolam tidak tegak lurus tapi umumnya mempunyai kemiringan $60^{\circ}$. Dengan konstruksi seperti itu, maka diambil asumsi bahwa volume efektif adalah sebesar $64 \%$ dari volume bila dinding kolam tegak lurus. Asumsi ini digunakan berdasarkan penghitungan-penghitungan volume dari bentuk limas terbalik dan terpotong pada kedalaman 6 meter. Dengan asumsi tersebut, maka volume efektif dari setiap unit kolam pemroses dapat dilihat pada Tabel 2. Diketahui bahwa air limbah PKS berasal dari Fat Pit dan juga berasal dari air bekas pencucian unit-unit pemroses dalam PKS. Idealnya kedua sumber air limbah ini dapat terukur semua jumlahnya atau debit alirnya secara pasti.

Tabel 2. Dimensi, Waktu Tinggal dan hasil analisa laboratorium pada proses pengolahan

\begin{tabular}{|c|c|c|c|c|c|c|c|c|c|c|c|c|c|c|}
\hline \multirow{3}{*}{ No } & \multirow{3}{*}{ NAMA UNIT } & \multicolumn{3}{|c|}{ DIMENSI (m) } & \multirow{3}{*}{$\begin{array}{c}\text { VOLUME } \\
\text { EFEKTIF } \\
\left(\mathrm{m}^{3}\right)\end{array}$} & \multirow{3}{*}{$\begin{array}{c}\text { WAKTU } \\
\text { TINGGAL } \\
\text { (hari) }\end{array}$} & \multicolumn{8}{|c|}{ KUALITAS (mg/liter) } \\
\hline & & \multirow[t]{2}{*}{$\mathbf{P}$} & \multirow[t]{2}{*}{$\mathbf{L}$} & \multirow[t]{2}{*}{$T$} & & & \multicolumn{4}{|c|}{ INFLUENT } & \multicolumn{4}{|c|}{ EFFLUENT } \\
\hline & & & & & & & COD & BOD & Ntot & Oil/Grease & $\operatorname{coD}$ & BOD & Ntot & Oil/Grease \\
\hline 1 & Cooling Pond 1 & 39 & 27 & 6 & 4.044 & 2,59 & & & & & & & & \\
\hline 2 & Cooling Pond 2 & 31 & 18 & 6 & 2.143 & 1,37 & & & & & & & & \\
\hline 3 & Cooling Pond 3 & 28 & 23 & 6 & 2.473 & 1,59 & 4.756 & 1.585 & 122 & 2.258 & & & & \\
\hline 4 & Acidification Pond & 95 & 37 & 6 & 13.498 & 8,65 & & & & & 196 & 65 & 98 & 69 \\
\hline 5 & Primary Anaerobic Pond 1 & 89 & 40 & 6 & 13.670 & 8,76 & & & & & 282 & 94 & 136 & 6 \\
\hline 6 & Primary Anaerobic Pond 2 & 89 & 40 & 6 & 13.670 & 8,76 & & & & & & & & \\
\hline 7 & Secondary Anaerobic Pond 1 & 52 & 35 & 6 & 6.989 & 4,48 & & & & & 170 & 57 & 128 & 32 \\
\hline 8 & Secondary Anaerobic Pond 2 & 70 & 52 & 6 & 13.978 & 8,96 & & & & & & & & \\
\hline
\end{tabular}

\subsection{Hasil Analisa Laboratorium Terhadap Kualitas Proses Pengolahan}

Pengambilan sample air limbah di sistem IPAL PKS PT. DMP yang telah dilakukan pada tanggal 30 Mei 2015 segera dianalisa di laboratorium yang terakreditasi nasional, yaitu PT. Global Quality Analitical. Hasil analisa kualitatif yang telah dilakukan di laboratorium tersebut dapat dilihat pada Tabel 2. Adapun informasi seluruh jenis sampel secara lengkap yang diambil pada saat survey sampling dapat dilihat pada Tabel $3 \mathrm{~s} / \mathrm{d}$ Tabel 6 . Berdasarkan SK Menteri LH No. 5 tahun 2014 tentang baku mutu limbah cair pabrik kelapa sawit, maka untuk parameter COD dan BOD untuk unit pemroses Asidifikasi dan anaerobik sudah memenuhi baku mutu, tetapi untuk parameter Oil/Grease pada unit Asidifikasi dan Kolam Anaerobik Sekunder masih melebihi baku mutu lingkungan ( $>30 \mathrm{mg} / \mathrm{l})$. Sementara itu untuk parameter Nitrogen Total semua unit pemroses masih jauh melebihi baku mutu lingkungan.

\subsection{Permasalahan Umum Pada Proses Pengolahan}

Berdasarkan kondisi eksisting IPAL dapat dipastikan bahwa permasalahan pertama yang menyebabkan munculnya permasalahanpermasalahan berikut dalam proses pengolahan air limbah adalah telah terjadinya pendangkalanpendangkalan pada seluruh kolam pemroses. Pendangkalan terberat terjadi pada kolam-kolam pemroses awal, yaitu ketiga kolam pendinginan, kolam asidifikasi dan keempat kolam anaerobik. Dengan terjadinya pendangkalan berat pada ketiga proses pertama tersebut, akibatnya air limbah tidak terolah sempurna dan hanya mengalir melalui beberapa saluran-saluran kecil yang disebut channel. Terjadinya pengaliran langsung air limbah melalui chanel kecil tersebut menyebabkan limbah tidak tinggal sesuai dengan waktu tinggal yang sudah direncanakan semula. Peristiwa terjadinya pengaliran air limbah yang hanya melalui chanel-channel kecil itu disebut sebagai Channelling.

Dengan pendekatan dan asumsi volume efektif dari setiap kolam adalah $64 \%$ dari volume 
kolam bila dinding kolam tegak lurus, maka sebenarnya IPAL untuk proses anaerobik masih memiliki Waktu Tinggal total, $\mathbf{T}_{\text {total }}=\mathbf{4 2 , 5 7}$ hari (lihat Tabel 2). Dengan Waktu Tinggal sebesar itu, maka proses pengolahan air limbah sesungguhnya masih dapat dijamin berlangsung dengan baik. Namun dengan terjadinya pendangkalan-pendangkalan di seluruh kolam pemroses, maka kondisinya menjadi sangat mengkhawatirkan karena proses pengolahan air limbah tidak akan berjalan dengan baik dan sempurna.

\subsubsection{Sistem Influent}

Sistem influent adalah sarana pengaliran atau transportasi air limbah dari sumber-sumber air limbah, yaitu dari Fat Pit dan air bekas pencucian unit-unit pemroses dalam PKS. Air limbah dari Fat Pit telah dilengkapi dengan Flow Meter, namun air bekas pencucian unit-unit pemroses tidak diketahui apakah juga dilengkapi dengan Flow Meter. Air limbah dari Fat Pit yang masih bertemperatur tinggi $\left(>60^{\circ} \mathrm{C}\right)$ dan mengandung Minyak \& Grease yang cukup tinggi (COD - BOD tinggi) perlu sarana pengaliran yang khusus. Sistem pengaliran yang terbuka dapat menyebabkan penurunan suhu dengan lebih cepat dan bila ini berlangsung, maka sepanjang saluran akan timbul penggumpalanpenggumpalan lemak/minyak sawit yang apabila tidak segera diangkat/diambil akan terakumulasi dan akan dapat menyebabkan penyumbatan pada saluran. Walaupun dialirkan dengan sistem tertutup (melalui sistem perpipaan dan dengan pompa) pengendapan gumpalan lemak tetap juga akan terjadi namun tidak sebanyak dan secepat bila dalam saluran terbuka. Endapan lemak atau minyak juga akan menurunkan efisiensi kinerja pompa, karena sudu-sudu atau propeller pompa akan terbebani. Karena itu sistem influent membutuhkan pemeliharaan yang optimal. Suasana yang sedikit asam dari air limbah yang berasal dari Fat Pit juga akan menyebabkan korosif. Unit Fat Pit terdiri dari 7 buah kolam dengan dimensi yang sama, yaitu lebar $3 \mathrm{~m}$, panjang $4 \mathrm{~m}$ dan kedalaman $1,75 \mathrm{~m}$. Volume total dari Fat Pit adalah $147 \mathrm{~m}^{3}$. Dengan rata-rata debit air limbah yang sebesar $65 \mathrm{~m}^{3}$ per jam, maka waktu tinggal air limbah dalam kolam Fat Pit sebesar 2,26 jam. Karena limbah ini mempunyai temperatur yang cukup tinggi dan sudah sangat lama beroperasi, maka kemungkinan besar dapat tumbuh mikro organisme thermofilik ${ }^{(8)}$. Karena itu kandungan bahan pencemar (COD dan BOD) yang berasal dari unit Fat Pit dapat terdegradasi secara bertahap di kolam-kolam Fat Pit, sehingga konsentrasi COD dan BOD dapat berkurang secara cukup berarti sebelum masuk ke dalam Kolam Pendingin.

\subsubsection{Kolam Pendinginan (Cooling Pond).}

Karena air limbah dari Fat Pit masih bertemperatur cukup tinggi maka dibutuhkan kolam pendinginan. Kolam pendingin yang seluruhnya terdiri dari 3 buah tersebut ternyata 2 kolam yang beroperasi dan pengoperasiannya secara paralel. Dari hasil analisa kualitatif (laboratorium) Kolam Pendingin ke 3 menunjukkan masih bersifat asam dengan $\mathrm{pH}=$ 4,45 (lihat Tabel 3).

Tabel 3 : Hasil analisa kualitatif Kolam Pendingin ke 3

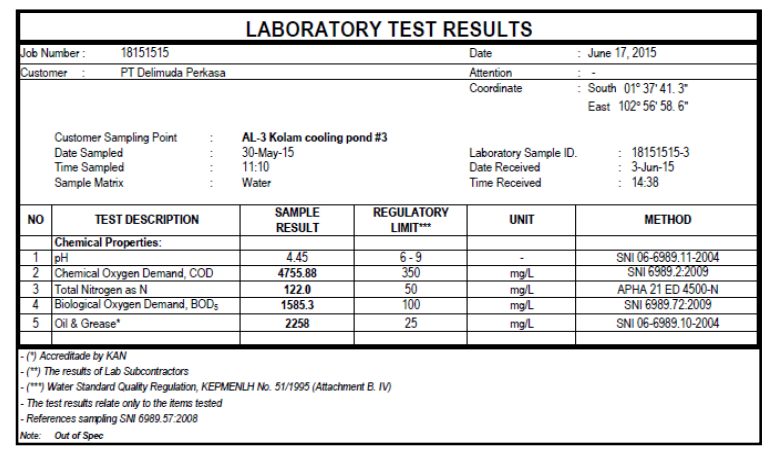

Hal ini sesuai dengan karakteristik derajad keasaman limbah cair pabrik CPO. Kandungan COD \& BOD yang tinggi $(4.756$ \& $1.585 \mathrm{mg} / \mathrm{l})$ dari Kolam Pendingin ke 3 ini sebenarnya masih tergolong rendah bila dibandingkan dengan umumnya limbah cair pabrik CPO (COD > 25.000 $\mathrm{mg} / \mathrm{l}$ dan $\mathrm{BOD}>20.000 \mathrm{mg} / \mathrm{l}^{(9)}$. Sementara untuk kandungan minyak/lemak dan $\mathrm{N}$ total menunjukkan nilai yang wajar. Kolam pendingin 2 \& 3 yang dioperasikan secara paralel mempunyai waktu tinggal total sebesar 2,96 hari, bila kedua kolam tersebut masih mempunyai volume efektif seperti yang ditunjukkan pada Tabel 2 .

Kondisi terkini dari kedua kolam pendingin tersebut menunjukkan bahwa telah terjadi pendangkalan secara masif, sehingga waktu tinggalnya pasti jauh di bawah dari 2,96 hari. Rendahnya waktu tinggal pada kolam pendingin juga dapat dilihat dari temperatur limbah cair yang masih tinggi bila dibandingkan dengan temperatur lingkungan. Dari hasil survei langsung pada tanggal 1 Juni 2015 diperkirakan temperatur air limbah dari Kolam Pendingin masih sekitar $40-45^{\circ} \mathrm{C}$. Dengan demikian Kolam Pendingin yang ada sekarang ini sudah tidak lagi dapat berfungsi dengan baik. Karena itu untuk menurunkan temperatur tersebut PT. DMP melakukan pencampuran air limbah dari Kolam Pendingin dan air limbah dari Kolam Aerobik dengan cara pemompaan air limbah dari Kolam Aerobik ke bagian pipa inlet Kolam Asidifikasi. Pencampuran tersebut tidak diketahui pasti dengan debit berapa air limbah yang dipompakan dari Kolam Aerobik. Karena adanya 
pencampuran ini, maka kualitas air limbah yang masuk ke dalam Kolam Pemroses selanjutnya (yaitu Kolam Asidifikasi) pasti akan mengalami pengenceran. Akibat adanya pencampuran ini juga tidak diketahui seberapa besar perubahan kualitas inlet ke Kolam Asidifikasi.

\subsubsection{Kolam Asidifikasi}

Seperti diuraikan di atas bahwa sebelum air limbah dari Kolam Pendingin masuk ke dalam Kolam Asidifikasi telah dilakukan pencampuran dengan air limbah dari Kolam Aerobik. Berdasarkan hasil analisa kualitatif terhadap air limbah di Kolam Asidifikasi terlihat bahwa $\mathrm{pH}$ telah menjadi normal, bahkan lebih dari 7 (yaitu $\mathrm{pH}=7,21)$. Nilai COD bahkan turun secara drastis, yaitu dari COD $4.756 \mathrm{mg} / \mathrm{l}$ menjadi hanya 196,35 mg/l. Demikian halnya dengan BOD dari $1.585,3 \mathrm{mg} / \mathrm{l}$ turun hingga $65,4 \mathrm{mg} / \mathrm{l}$. Dengan demikian untuk parameter BOD dan COD pada Kolam Asidifikasi ini sudah memenuhi baku mutu sesuai dengan peraturan yang berlaku. Sementara itu nilai Oil \& Grease juga terjadi pengurangan drastis, yaitu dari $2.258 \mathrm{mg} / \mathrm{l}$ menjadi $68,8 \mathrm{mg} / \mathrm{l}$. Hasil analisa ditunjukkan pada Tabel 4.

Untuk nilai $\mathrm{N}$ total penurunannya tidak sedrastis penurunan COD, BOD dan Oil \& Grease. Melihat adanya penurunan drastis tersebut diperkirakan telah terjadi penyimpangan.

Penyimpangan pertama adalah karena adanya pencampuran air limbah. Perbandingan kuantitas tidak diketahui secara pasti, demikian juga tentang kualitas air limbah setelah pencampuran. Air limbah yang berasal dari Kolam Aerobik sebenarnya mengandung banyak mikroba aerobik dan apabila dicampurkan dan dimasukkan ke Kolam Asidifikasi dengan suasana yang sangat asam $(\mathrm{pH}=4,45)$ dan kondisi peralihan, maka mikroba-mikroba Aerobik yang terkandung dalam air limbah akan mengalami deaktivasi atau bahkan mati. Untuk optimalisasi proses pengolahan ini seharusnya suasana keasaman dinetralkan lebih dahulu dan bila tidak dinetralkan akan timbul penyimpangan $^{(10)}$.

Penyimpangan kedua adalah pada penentuan pengambilan titik sampling pada Kolam Asidifikasi. Apakah sudah mewakili kondisi keseluruhan dari Kolam Asidifikasi? Dikhawatirkan telah pula terjadi kesalahan dalam sampling, karena sebagian besar permukaan Kolam Asidifikasi telah mengalami pengendapan pada permukaannya, sehingga air limbah yang mengalir akan masuk di bawah endapan pada permukaan dan situasinya akan berubah menjadi anaerobik, karena tidak adanya oksigen. Dengan demikian bakteri aerobik akan mati karena tidak adanya oksigen. Melihat seluruh kolam proses dalam IPAL yang terbuka, maka bila hujan turun cukup lama dan dengan intensitas curah hujan yang cukup besar akan dapat mengencerkan air limbahnya. Karena itu dikhawatirkan juga telah terjadi penyimpangan pengambilan sampel pada titik yang merupakan genangan air yang didominasi oleh air hujan, sehingga berakibat terjadi pengenceran secara berarti

Tabel 4 : Hasil analisa kualitatif Kolam Asidifikasi

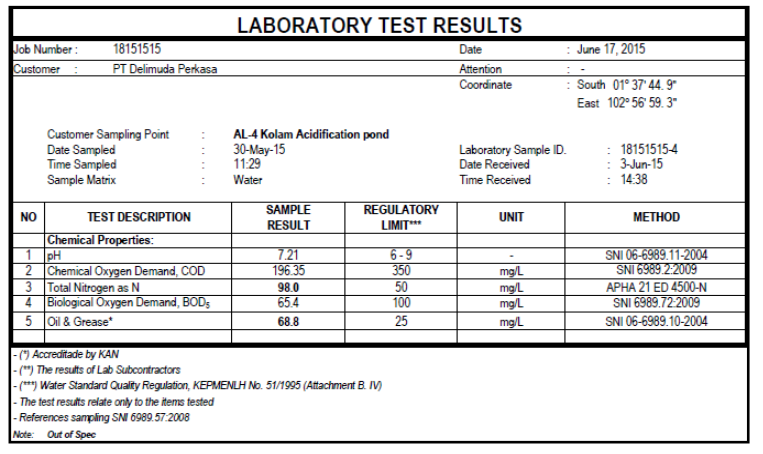

Waktu tinggal air limbah dalam Kolam Asidifikasi sebesar 8,65 hari, dengan asumsi bila volume efektifnya sesuai seperti pada Tabel 2. Bila volume efektif Kolam Asidifikasi sudah berkurang jauh karena adanya pendangkalan secara berarti, maka untuk mengetahui efektivitas proses pengolahan harus dilakukan pengambilan titik sampling pada titik inlet dan outletnya.

\subsubsection{Kolam Anaerobik}

Kolam Anaerobik terdiri dari 4 buah kolam, yaitu 2 Kolam Anaerobik Primer dan 2 Kolam Anaerobik Sekunder. Pengambilan titik sampling dilakukan pada Kolam Anaerobik Primer yang pertama dan Kolam Anaerobik Sekunder yang pertama. Hasil analisa laboratorium pada kedua kolam tersebut dapat dilihat pada Tabel $5 \& 6$.

Tabel 5 : Hasil analisa kualitatif Kolam Anaerobik Primer ke 1

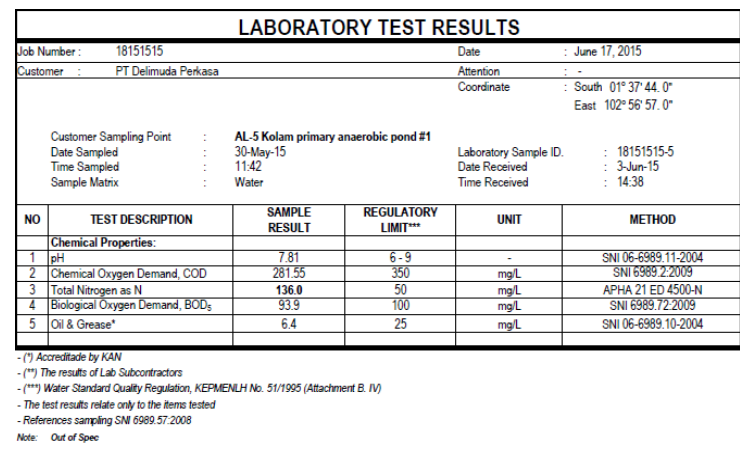

Berdasarkan hasil analisa kualitatif laboratorium dijumpai ketidakwajaran, dimana kualitas air limbah pada Kolam Asidifikasi lebih 
baik dari pada kualitas air limbah pada Kolam Anaerobik primer. Seharusnya yang terjadi adalah kebalikannya, karena Kolam Anaerobik beroperasi setelah Kolam Asidifikasi. Jadi untuk 3 parameter COD, $\mathrm{N}$ total dan BOD bahkan terjadi kenaikan dari Kolam Asidifikasi ke Kolam Anaerobik Primer (masing-masing dari COD 196,36 ke 281,55 mg/l, $\mathrm{N}$ total dari $98 \mathrm{ke} 136$ $\mathrm{mg} / \mathrm{l}$ dan BOD dari 65,4 ke 93,9 mg/l).

Tabel 6 : Hasil Analisa kualitatif Kolam Anaerobik sekunder ke 1

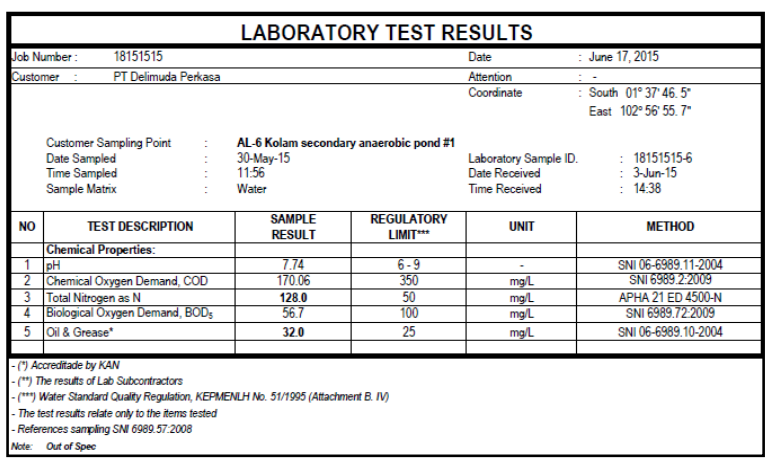

Hal itu mungkin saja terjadi mengingat sebelumnya telah dibahas bahwa telah terjadi kemungkinan penyimpangan terhadap kesalahan pengambilan titik sampling pada Kolam Asidifikasi. Karena itu kondisi ideal yang seharusnya dilakukan adalah melakukan pengambilan sampel pada titik inlet dan outlet setiap unit Kolam Pemroses. Hasil analisa kualitatif terhadap kualitas air limbah dari Kolam Anaerobik Primer ke Kolam Anaerobik Sekunder juga menunjukkan adanya penyimpangan yang sama, yaitu nilai Oil \& Grease yang sangat rendah pada Kolam Anaerobik Primer (6,4 mg/l) berubah atau meningkat menjadi $62,0 \mathrm{mg} / \mathrm{l}$ pada Kolam Anaerobik Sekunder. Tetapi untuk 3 parameter yang lain, yaitu COD, $\mathrm{N}$ total dan BOD proses perubahannya menunjukkan hasil yang wajar, artinya ada pengurangan.

Dilihat dari waktu tinggal pada masingmasing kolam anaerobik sebenarnya sudah sangat memenuhi kriteria desain yang benar, bahkan secara keseluruhan ke 4 Kolam Anaerobik mempunyai waktu tinggal sebesar 30,96 hari. Jumlah ini sudah sangat jauh lebih besar dari yang dibutuhkan secara normal ${ }^{(11)}$. Namun diketahui bahwa karena telah terjadi pendangkalan secara masif di hampir setiap kolam pemroses (terutama pada tiga proses pertama, yaitu Pendinginan, Asidifikasi dan Anaerobik), maka berbagai kemungkinan kesalahan atau kerancuan dalam hasil analisa kualitatif dapat terjadi penyimpangan. Berdasarkan informasi dari pihak pengelola IPAL bahwa pernah dilakukan pengerukan di beberapa Pond pada tahun 2009. Namun dari hasil survei dan pengamatan langsung, terlihat bahwa masalah pengendapan lumpur yang menyebabkan pendangkalan di setiap Kolam Pemroses merupakan sumber penyimpanganpenyimpangan yang terjadi.

\subsection{Alternatif Penanggulangan Masalah}

Penanggulangan masalah dalam proses pengolahan air limbah (IPAL) PKS PT. DMP dapat ditempuh melalui dua alternatif, yaitu melakukan perbaikan (termasuk pemeliharaannya) unit-unit pemroses secara minimal atau sederhana dan melakukan perbaikan secara maksimal (total). Tentu saja alternatif pertama membutuhkan biaya yang jauh lebih rendah dibandingkan melaksanakan alternatif kedua.

\subsubsection{Alternatif Perbaikan Minimal dan Sederhana}

Upaya perbaikan minimal atau sederhana terdiri dari tahapan-tahapan berikut:

\section{a. Pengerukan Seluruh Kolam Pemroses}

Seperti telah diuraikan sejak awal dalam pembahasan ini bahwa telah terjadi pendangkalan secara masif pada hampir seluruh kolam pemroses, sehingga menyebabkan volume efektifnya berkurang jauh dan waktu tinggal (detention time) air limbah dalam proses di setiap unit pemrosesnya menjadi lebih singkat dari yang telah direncanakan semula dalam Master Plan IPAL ini. Pendangkalan terjadi akibat pengendapan lumpur pada bagian bawah setiap kolam dan juga pada bagian permukaan kolam karena proses flotasi dari gumpalan-gumpalan minyak/lemak yang berat jenisnya lebih kecil dari pada air. Pendangkalan yang paling berat memang terjadi pada kolam-kolam pemroses awal, yaitu Kolam Pendinginan, Kolam Asidifikasi dan Kolam Anaerobik. Bahkan pada saat ini Kolam Pendinginan yang pertama sudah tidak dapat digunakan lagi, karena memang lumpur endapan sudah memenuhi seluruh volume kolam dan telah terjadi pengerasan permanen. Pengerukan lumpur endapan sebaiknya dilakukan secara periodik (berkala) setiap tahun sekali atau setiap dua tahun sekali. Pengerukan dilakukan sehingga volume efektif dapat kembali ke ukuran semula sesuai Master Plan yang sudah ditentukan sebelumnya.

Bila pengerukan dan pengambilan lumpur endapan dilakukan, sebenarnya lumpur tersebut dapat dimanfaatkan untuk keperluan land application, yaitu penggunaan lumpur untuk keperluan pemupukan lahan pohon-pohon kelapa sawit dalam areal perkebunan yang dimiliki. Biasanya untuk pemanfaatan lumpur endapan ini, lebih dahulu harus disiapkan parit- 
parit dengan kedalaman $1,5 \mathrm{~m}$ dan lebar $2 \mathrm{~m}$ yang membujur sepanjang alur tanaman pohon kelapa sawit. Antar parit lumpur endapan ini bisa berjarak 40 hingga 50 meter. Skema untuk land application ditunjukkan pada Gambar 4. Ada juga yang membuat sistem parit untuk land application ini di sepanjang tepian setiap blok penanaman pohon kelapa sawit. Sistem land application dalam memanfaatkan lumpur endapan untuk keperluan pemupukan lahan tanaman pohon kelapa sawit dapat dilihat pada Gambar 4.

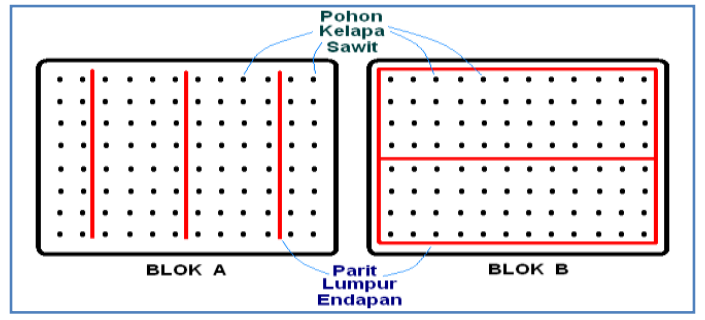

Gambar 4. Sistem Land Application untuk pemanfaatan lumpur endapan sebagai pupuk.

\section{b. Perbaikan Sarana Inlet dan Outlet}

Tata letak dari kolam-kolam pemroses seperti yang telah ditunjukkan pada Gambar 1, memperlihatkan aliran air limbah terolah dari setiap kolam ke arah kolam pemroses berikutnya. Artinya setiap kolam pemroses mempunyai sistem inlet dan outlet. Karena bentuk kolam pada umumnya adalah persegi empat, maka saluran aliran air limbah yang masuk ke dalam suatu kolam pemroses (bagian inletnya) hendaknya juga terdistribusi merata mulai dari sisi masuknya, kemudian pengaliran di dalam unit kolam pemroses, hingga pada akhir sisi yang lain dari kolam pemroses tersebut yang juga mempunyai sistem outlet yang seimbang. Dengan cara pendistribusian merata mulai dari inlet sampai pada outletnya, maka kemungkinan deadspace pada bagian sudut-sudut setiap kolam pemroses akan diminimalisir. Demikian juga pada sistem outletnya. Dengan cara seperti itu terjadinya pengendapan juga akan lebih merata di setiap bagian kolam pemroses. Secara skematik, sistem inlet-outlet ditunjukkan pada Gambar 5.

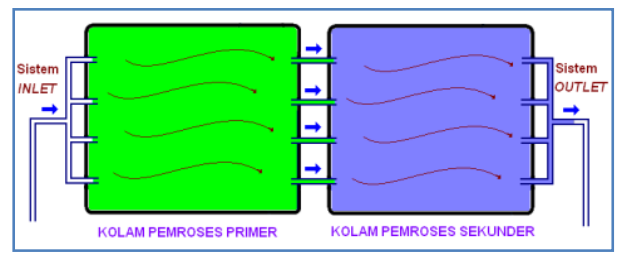

Gambar 5. Skema sistem inlet-outlet dari satu kolam pemroses ke kolam pemroses berikutnya.

\section{c. Pemasangan Flow Meter}

Jumlah air limbah yang masuk ke dalam IPAL PKS umumnya berasal dari dua sumber, yaitu dari Fat Pit dan air limbah bekas pencucian seluruh unit-unit pemroses dalam pabrik. Apabila kedua sumber ini masuk melalui satu sistem saluran, maka cukup dibutuhkan sebuah flow meter. Tetapi apabila kedua sumber air limbah mempunyai saluran terpisah, maka selayaknya juga harus terpasang di setiap saluran air pembuangan dari PKS tersebut. Untuk jumlah air limbah terolah yang keluar dari sistem IPAL tentunya juga harus terukur secara terus menerus (kontinu) pada bagian Kolam Akhir yang kedua. Jumlah air limbah yang diolah dalam IPAL akan berkurang sejalan dengan urutan proses pada sistem pengolahan air limbah. Pembentukan endapan selama pengolahan akan mengurangi jumlah material total yang mengalir sampai ke kolam yang terakhir. Karena semua unit-unit pemroses yang berupa kolam dalam IPAL PKS merupakan kolam terbuka, maka ada faktor lain yang juga mempengaruhi jumlah air limbah yang diolah, yaitu musim. Pada musim kemarau, efek penguapan air akan mempengaruhi walaupun sangat sedikit. Namun pada musim hujan jumlah air limbah akan bertambah dengan cukup berarti dan secara kualitas akan lebih baik karena adanya efek pengenceran dari air hujan. Bagaimanapun kondisinya, maka setiap IPAL haruslah memiliki Flowmeter untuk dapat mengetahui secara pasti jumlah air terolah yang keluar dari sistem IPAL PKS.

\subsubsection{Alternatif Perbaikan Maksimal}

\section{a. Remining Pond}

Istilah Remining Pond dimaksudkan melakukan pengambilan seluruh endapan lumpur yang sudah mengeras di setiap kolam. Untuk melaksanakan ini dapat dilakukan secara bergantian, misalnya Kolam Pendingin yang terdiri dari 3 buah kolam, maka pada saat kolam pertama dikuras secara total, kolam kedua dan ketiga masih tetap dapat dioperasikan. Kemudian setelah selesai dengan pengurasan kolam pertama, dilanjutkan dengan kolam kedua. Demikian pula untuk Kolam Anaerobik Primer dan Sekunder juga dapat dilakukan pengurasan total secara bergantian. Namun untuk Kolam Asidifikasi yang hanya sebuah, maka pada saat proses pengurasan totalnya, untuk sementara dapat digantikan dengan menggunakan Kolam Pendingin ketiga.

\section{b. Rekonstruksi IPAL}

Rekonstruksi IPAL dimaksudkan agar dapat mencegah pencemaran air limbah terhadap air 
tanah. Rekonstruksi dilakukan dengan memasang bahan-bahan pelapis secara bertingkat, yaitu dari Geoliner (HDPE = High Density Poly Etylene), Geomembran dan Geotextile pada dasar dan dinding kolam. Untuk melaksanakan rekonstruksi tersebut tentu dibutuhkan biaya yang cukup besar, namun hal ini untuk menjamin agar tidak ada lagi rembesan air limbah yang meresap masuk ke dalam tanah dan akhirnya mencemarkan air tanah.

\section{KESIMPULAN}

Permasalahan utama dalam IPAL PKS PT. DMP pada sistem anaerobiknya adalah terjadinya pendangkalan secara masif di seluruh proses, dari Kolam Pendingin hingga Kolam Anaerobik Sekundernya. Kedalaman setiap kolam yang seharusnya $6 \mathrm{~m}$, kenyataannya hanya tersisa menjadi $1,5 \mathrm{~m}$, sehingga yang terjadi adalah Channelling, yaitu air limbah masuk ke satu unit proses dan terus mengalir melalui suatu saluran (channel) pada bagian permukaannya saja, tanpa menempuh waktu tinggal yang cukup. Masalah lainnya yang menimbulkan penyimpangan adalah dicampurkannya air limbah dari Kolam Pendingin ketiga dengan air limbah yang berasal dari Kolam Aerobik dan kemudian masuk ke dalam Kolam Asidifikasi. Karena suasana keasaman yang cukup rendah, maka bakteri aerob yang berasal dari Kolam Aerobik tidak akan mampu melakukan aktivasi atau bahkan dapat mati.

\section{PERSANTUNAN}

Kegiatan ini dapat terlaksana berkat bantuan dari pimpinan dan staf dari BLHD Propinsi Jambi dan juga pimpinan Divisi Limbah PKS PT. DMP yang telah mendukung penuh dalam pembiayaan penelitian ini. Selayaknya penulis mengucapkan terima kasih.

\section{DAFTAR PUSTAKA}

1. Muryanto, Y. Sudiyani dan H. Abimanyu, (2016), Optimasi Proses Perlakuan Awal $\mathrm{NaOH}$ Tandan Kosong Kelapa Sawit untuk menjadi Bioetanol, Indonesia J. App. Chem., Vol. 18 (1), pp. 27-35, June 2016, p-ISSN: 0853-2788, e-ISSN: 2527-7669, Accreditation number : 540/AU1/P2MI LIPI/06/2013

2. Anonim, (2013), Laporan Pemantauan Kualitas Lingkungan Daerah, BLHD Kab. Batanghari, Semester I.

3. Anonim, (2013), Laporan Pemantauan Kualitas Lingkungan Daerah, BLHD Kab. Batanghari, Semester II.
4. Hendriyanto, (2013), Kades Minta Pemkab Tegas Soal Pencemaran PT. DMP, http://kabarbatanghariberlianonline.blogspot. co.id, Jumat, 29 Maret 2013.

5. Widarti B.N., S. H. Susetyo, E. Sartwono, (2015), Degradasi COD Limbah Cair Dari Pabrik Kelapa Sawit Dalam Proses Pembentukan Biogas, Jurnal Integrasi Proses, Vol 5 No. 3, Prodi Teknik Lingkungan, Fak. Teknik, Univ. Samarinda, Desember 2015.

6. Irvan, I. Suraya, H. Tiarasti, B. Trisakti, R. Hasibuan, Y.Tomiuchi, (2012), Pembuatan Biogas dari Berbagai Limbah Cair Pabrik Kelapa Sawit, Jurnal Teknik Kimia, USU, Vol. 1 No. 1, Medan.

7. Anonim, (2007), Laporan Sistem Pengolahan Air Limbah Semester 1 Tahun 2007/2008, Divisi Pengolahan Air Limbah PT. DMP Jambi, Desember 2007.

8. Sutiamiharja, N. (2008), Isolasi Bakteri dan Uji Aktifitas Amilase Kasar Termofilik dari Sumber Air Panas Gurukinayan, Karo sumatera Utara, Tesis, Sekolah Pasca Sarjana, USU, Medan.

9. Wahyudi P. (1998), Karakteristik Limbah Cair Pabrik CPO, PPKS, Medan.

10. Rahardjo, P.N., (2008), Pengolahan Limbah Cair Pabrik Kelapa Sawit dengan Bioreaktor Anaerobik Biakan Melekat Dalam Skala Laboratorium. Pengamatan Pengurangan BOD, COD dan TSS dengan Variabel Waktu Tinggal, Jurnal Teknologi Lingkungan, Edisi Khusus, Jakarta.

11. Rahardjo, P.N., (2009) , Studi Banding Teknologi Pengolahan Limbah Cair Pabrik Kelapa Sawit, Jurnal Teknologi Lingkungan, Vol. 10 No. 1, Jakarta, Januari 2009.

12. Nursanti W., D. Budianta, A. Napoleon dan Y. Parto, (2013), Pengolahan Limbah Cair PKS Kolam Anaerob Sekunder I Menjadi Pupuk Organik Melalui Pemberian Zeolit, Seminar Nasional Sains \& Teknologi V, Lembaga Penelitian Universitas Lampung, 19-20 November 2013

13. Purwanti, S .Elystia dan A. Sasmita (2014), "Pengolahan Limbah Cair PKS Dengan Metoda Fitoremediasi Menggunakan Typha Latifolia", Jurnal JOM FTEKNIK Volume 1 No.2 Oktober 2014, Fak. Teknik Universitas Riau, Pekanbaru. 